\title{
Social interactions in transportation: analyzing groups and spatial networks
}

\author{
Frank Goetzke ${ }^{1} \cdot$ Regine Gerike $^{2} \cdot$ Antonio Páez $^{3}$ • \\ Elenna Dugundji ${ }^{4}$
}

Published online: 2 September 2015

(C) Springer Science+Business Media New York 2015

Keywords Personal and activity networks $\cdot$ Social influence $\cdot$ Social network analysis · Individual interactions · Aggregate interactions

\section{Introduction}

Travel demand is derived from activities that people have to or want to engage in. Work trips have been a primary concern for transportation researchers and an early focus of transportation modeling was on commuting behavior (Ben-Akiva and Lerman 1974; Train 1980). Subsequently, non-work activities, such as shopping or doctor visits, increasingly caught the attention of transportation analysts, and interest shifted from a trip-purpose approach (i.e. work trips) towards scheduled-based travel analysis (Bhat and Koppelman 1999). However, these activity trips all have in common that they still could be modeled without considering social context. The analysis approach of choice behavior was rooted in neoclassical economics assuming methodological individualism of isolated, utility-maximizing agents (Small and Winston 1999).

While using the traditional neoclassical tool box, much has been learned about journeys to work and trip scheduling for non-work activities. Early research in intra-household interactions in travel demand modeling focused on coordination of individual daily activity patterns, joint participation in activities and travel, mechanisms for allocation of maintenance activities, and activity location and residential location choice behavior (Scott and

Frank Goetzke

f0goet01@louisville.edu

1 University of Louisville, Louisville, KY, USA

2 Dresden University of Technology, Dresden, Germany

3 McMaster University, Hamilton, ON, Canada

4 CWI - National Research Institute for Mathematics and Computer Science, Amsterdam, The Netherlands 
Kanaroglou 2002; Gliebe and Koppelman 2002, 2005; Bradley and Vovsha 2005; Srinivasan and Bhat 2005; Bhat and Pendyala 2005; Timmermans and Zhang 2009; Arentze and Timmermans 2009). It is more recently that a social context of traveling choices, such as meeting friends, visiting events (i.e. sport games, concerts, theater, etc.), or engaging in other social activities (church, sports club, volunteering), has begun to receive attention and has been integrated into activity-based modeling (Arentze and Timmermans 2008; Ronald et al. 2012). This mirrors an important development in many regions around the world where the share of leisure trips is rising. It is one main motivation why transportation researchers have become more interested in studying personal and activity networks in general, as well as in adopting a social network perspective in transportation research specifically (Kowald and Axhausen 2015). A parallel development has been on modeling social influence where other social science approaches, including network analysis or social interaction modeling, increasingly are adopted as a complement to the traditional utilitymaximizing approach in travel demand analysis (Bhat and Sener 2009; Abou-Zeid and BenAkiva 2011; Bhat and Sidharthan 2011; Sidharthan et al. 2011; Walker et al. 2011; Goetzke and Weinberger 2012; Whalen et al. 2012; Kamargianni et al. 2014; Kroesen 2015).

The basic idea of bringing social networks into transportation analysis is straightforward: An increasing number of trips today are undertaken that no longer can be seen as if they were individualistic and disconnected as neoclassical theory assumes, but should rather be seen in a web of social relations and context (Dugundji and Walker 2005; Páez and Scott 2007; Carrasco and Miller 2006, 2009; Axhausen 2008; Arentze and Timmermans 2008; Goetzke 2008). In this context, a distinction can be made between identifiable versus aggregate interactions (Dugundji and Gulyas 2003a, b).

- We speak of interaction between "identifiable" decision-makers when the links in the network are well-known and explicitly defined on an individual decision-maker by decision-maker basis. For example, working parents may have to negotiate who drops off their child at school or who picks their infant up from nursery (Schwanen 2008; Ho and Mulley 2015). Likewise, the fastest growing segment of travel, leisure trips, requires knowledge of social context for the analysis of travel demand (Kowald and Axhausen 2012). An understanding of friendship networks will help predicting how often, when and where friends meet, and thus the corresponding generated trips (Carrasco et al. 2008; Kowald et al. 2013).

- We speak of interaction between "aggregate" decision-makers when interdependence is assumed to take place only at an aggregate level with links being defined by implicit networks, for example, more generally based on decision-maker characteristics, by latent constructs or by studying behavior of abstract classes of social and/or spatial networks. Some explorations of the dynamic behavior of such a model include Páez et al. (2008), Dugundji and Gulyás (2008, 2013). Some examples of the empirical estimation of such a model include Fukuda and Morichi (2007), Adjemian et al. (2010), Bhat et al. (2010), Sener et al. (2010), Goetzke and Andrade (2010), Goetzke and Rave (2011), Kuwano et al. (2011), (2012). Dugundji and Gulyás (2012a, b), Scott et al. (2012), Sener and Bhat (2012), Sidharthan and Bhat (2012), Paleti et al. (2013)

In order to exchange and further develop this research, an interdisciplinary group of scholars and practitioners came together in 2005 for the first "International Workshop: Frontiers in Transportation-Social and Spatial Interactions" in Amsterdam, Netherlands (Dugundji et al. 2008), followed by another workshop 2 years later again in Amsterdam, Netherlands (Dugundji et al. 2011). The next two workshops, in 2009 (Dugundji et al. 2012) and in 2011 (Scott et al. 2013) were held in Niagara-on-the-Lake, Canada. In 2013 
an important survey article on mass effects and mobility decisions summarized research progress in the field (Abou-Zeid et al. 2013). In 2014, a special issue on social context of travel behavior was also published (Carrasco and Farber 2014). Taken together this shows the steady maturity of research questions on social networks, interactions and spillovers in transportation during the last decade.

\section{The contributions}

The eight papers collected in this special issue are a selection of the work presented during the International Workshop "Frontiers in Transportation - Social Interactions" at Herrsching am Ammersee near Munich, Germany, which was held in 2013. The topics represent the breadth of the research in the field of social interactions in transportation, spanning analysis of groups and spatial networks, and identifiable and aggregate interactions. The relations between these papers can be roughly conceptualized as in Table 1 .

The first four papers in this special issue deal primarily with socio-group networks. This research focuses on non-spatial relations between people, and how their interactions influence travel behavior. Two of these articles are motivated by a goal of incorporating social network dynamics, and decisions made in inter- and intra- household networks, in travel behavior simulation models. Sharmeen et al. (2015) develop a dynamic life cycle event model of friendship using a random utility maximization framework to predict the formation of a tie between two individuals. Using a Dutch dataset, the authors find that homophily as well as geographic proximity play an important role in the formation of friendship networks. This kind of research can be used, for example, to forecast recreational trips within a travel behavior simulation model.

Dubernet and Axhausen (2015) develop a game theoretic framework for the study of joint decision making and present a validation run where intra-household interactions are included into the MATSim activity-based, multi-agent travel microsimulation tool. Using data from the Zürich, Switzerland area and focusing on the possibility of joint trips, they find that the simulation performs reasonably well replicating the passenger mode shares for mandatory trips, but less so for discretionary trips.

The second two articles have an empirical focus with attention to policy implications. The study by Matous et al. (2015) centers on information diffusion in personal networks. Based on data of rural Indonesian coffee and cacao farmers, the authors investigate how agricultural information is obtained. The mode of contact could be telecommunication (mobile phone), walking or motorized transportation (mainly motor bikes). Applying a hierarchical logit model, complemented by in-depth interviews, their results reveal the following insights: the farmers strongly favor face-to-face contact; and mobile phones are predominately used to arrange and coordinate meetings with distant information sources.

Table 1 Social interactions in transportation: Contributions in this special issue

\begin{tabular}{lll}
\hline $\begin{array}{l}\text { Social interactions in } \\
\text { transportation }\end{array}$ & Identifiable individuals/agents & Aggregate effects \\
\hline Socio-group networks & $\begin{array}{l}\text { Sharmeen (2015); } \\
\text { Dubernet and Axhausen (2015) }\end{array}$ & $\begin{array}{l}\text { Matous et al. (2015); } \\
\text { Goetzke and Rave (2015) } \\
\text { Networks which have socio- } \\
\text { spatial characteristics }\end{array}$ \\
\hline
\end{tabular}


Also, the farmers prefer motorized transportation relative to walking to save time when contacting distant information sources. Motorbikes enable the farmers to reach outside the circle of their strong relationships which are maintained by walking and facilitate social contact between diverse communities. Furthermore, people with motorbikes have significantly more extensive extra-communal access to information and weak evidence suggests that they also have less contact within their communities.

Peer networks, defined by age group, education attainment and residential location, are the research topics of the article by Goetzke and Rave (2015). Based on German data and using a happiness regression approach, they investigate how much peers' average automobile availability has an impact on a person's quality of life. They find that, in general, subjective well-being increases with own automobile access, but decreases with peers' higher automobile access. However, when own automobile access is measured as the deviation from the peers' access, the results point to the fact that especially the difference in automobile availability with respect to peers makes a person worse off. Therefore, happiness depends on whether a person and the peers are in a similar situation or not. This finding supports the idea that automobile ownership poses a "positional" externality.

The remaining four papers deal predominately with networks which have socio-spatial characteristics, such as neighborhood or distance relations. Two of these studies focus on local and "small-world" networks, which combine the spatial with the previously discussed social group characteristics. Van den Berg et al. (2015) examine to what extent local social interactions are affected by characteristics of the residential environment as well as personal and mobility attributes. Based on a two-day social interaction diary for residents in the Eindhoven, Netherlands metro area and using a multi-level binomial logit model, the authors conduct an analysis of whether or not an interaction took place within the immediate neighborhood. They find that contact with a fellow local resident is increasing for older people, females, larger households and full-time employed, but is decreasing for households with more vehicles, and somewhat, for longer commuting time. Social interactions also correlate positively with the existence of a nearby supermarket, primary school and outdoor sport facility, as well as with suburban residential location (outside of the central city Eindhoven).

Small-world networks use spatial proximity in graphs to represent social interaction. This is the approach taken by Okushima (2015), who investigates the shift towards sustainable mobility choices among heterogeneous agents. He uses outcomes from a stated preference questionnaire to estimate a binary mode choice model for car versus sustainable transport (bus rapid transit)., the author subsequently feeds the results into a multi-agent simulation model and finds that many households show conformity in their mobility choices, however, when allowing for heterogeneity among agents, also non-conformity is observed. In addition, the simulation reveals that heterogeneity decreases share of sustainable transport. The simulation model also supports the idea that green tax policies are superior to cordon pricing and distance-based pricing in terms of achieving higher sustainable transport mode share.

The last two articles are methodological in nature. Joubert and Meintjes (2015) investigate the properties of freight networks. Using GPS-based truck origin-destination data for the Nelson Mandela Bay Municipality in South Africa, linked with facility location, the authors create a complex network, resembling the interactions between firms in a supply chain system, which they then studied using network analysis tools. Having nodes signifying firms and the edges of the network representing the connections between firms, they evaluated how density-based clustering parameters influence the completeness of the network, as well as the computational burden of the network. These results are 
valuable to understand the capacity of current software and computer technology in conveniently implementing analysis methods that can introduce a social/spatial network perspective to transportation studies.

Bhat (2015) develops a spatial multinomial probit technique that extends the traditional panel discrete choice model to include social/spatial dependencies. This formulation accommodates spatial drift effects, which consists of both the spatial structure on individual-specific unobserved preference as well as the spatial structure on individual-specific response sensitivity, and is originating from endogenous group formation. This mode choice model approach allows for the possibility of residential self-selection (or spatial drift) of individuals based on mode-use propensities. In a simulation study the author finds that the estimator is efficient and the asymptotic formula performs well in estimating the finite sample standard errors. Furthermore, the results highlight the bias in estimates if spatial lag and/or spatial drift effects are ignored when both are actually present.

\section{Moving forward}

While the research subjects of all eight studies are diverse, they all use empirical data and/ or quantitative methods. The themes of these papers provide an overview of how broad the topics are, reaching from studying the diffusion of agricultural information in Indonesia, to identifying peer effects in Germany, to analyzing sustainable mobility in Japan, to measuring the relation between social contact distance patterns, personal characteristics, mobility and the built environment in the Netherlands. Yet, at the same time, the approaches in the field of social interactions and transportation are unified. For example, more than half of the studies included in this special issue use survey-based micro data which are then analyzed with the help of discrete choice regression modeling.

Social interactions and transportation research has greatly benefited from bringing in concepts from other fields into their own subject area. Goetzke and Rave (2015) bring in the concept of positional externalities from public economics to their research on subjective well-being in travel behavior, which in itself draws on a stream of research in psychology. Also interesting to observe is how social spillover analysis borrows from spatial regression modeling, as demonstrated by Bhat (2015). Persons within a group or different groups are examined in analogy to more or less distant spatial neighbors. This helps addressing some of the otherwise difficult to solve issues and turns out to be a successful cross-fertilization of two sub-disciplines of econometrics. Matous et al. (2015) complement their quantitative analysis of a multilevel multivariate logistic model with qualitative data from classical semi-structured interviews from social science for a nuanced assessment of the impact of policies. Dubernet and Axhausen (2015) draw on co-evolutionary principles from natural computing to develop an algorithm to efficiently search approximate solutions for their framework for joint decision making, which in turn is inspired by game theory. Sharmeen et al. (2015) propose a model of social network evolution inspired by life course theory and concepts from social network analysis, in a novel cross-fertilization from sociology, which is then brought to a utility-maximizing framework. In a comprehensive multi-agent based social simulation model, Okushima (2015) uses results from combined revealed and stated preference estimation, a hierarchical Bayesian model and two hazard-based duration models.

It is encouraging to see new topics arise in the field of social interactions and transportation, such it is the case in this special issue in the paper which extracts and analyzes inter-firm supply chain networks in South Africa from traces of on-board GPS devices of 
commercial vehicles. More of this innovative exploration of social network analysis applied to freight mobility as a complement to the stream of existing research in social interactions in passenger travel is welcome. Also, while a current focus in the field is on travel behavior and personal interactions in friendships, group and neighborhood networks, intra-household interactions, involving vehicle purchase decisions, activity choices, tour planning and the "governance" of mobility needs, as well as interactions in the society-atlarge are less explored. Society-at-large interactions comprise inquiries, for example, about the link of social capital and transportation choices (Carrasco and Cid-Aguayo 2012), or social attitudes and transportation policies. At the same time, use of modern information and communication technology such as smart phones and social media applications provide a unique opportunity to collect mobility and social interaction behavior data longitudinally and at wide scale. We as the guest editors are looking forward to future studies addressing these research questions which are highly relevant for transportation planning applications and policy decision making.

Acknowledgments We would like to thank all authors and participants in the Herrsching am Ammersee workshop for their contributions, ideas, and constructive criticism, as well as the other members of the convening committee beyond the guest editors of this special issue, Theo Arentze, Kay Axhausen, Juan Carrasco, Pat Mokhtarian and Darren Scott. We are grateful to Mark W. Horner, our liaison editor at Transportation, for valuable support and guidance throughout the development of this theme issue. We also want to express thanks to Martin Richards, the former editor-in-chief of Transportation, for backing our idea of a special issue and generously approving it. The International Workshop "Frontiers in TransportationSocial Interactions" held in 2013 at Herrsching am Ammersee near Munich, Germany was funded in part by the German Research Foundation (DFG) and hosted by the Institute for Transport Studies at the University of Natural Resources and Life Sciences (BOKU) Vienna.

\section{References}

Abou-Zeid, M., Ben-Akiva, M.: The effect of social comparisons on commute well-being. Transp. Res. Part A Policy Pract. 45(4), 345-361 (2011)

Abou-Zeid, M., Schmöcker, J.D., Belgiawan, P.F., Fujii, S.: Mass effects and mobility decisions. Transp. Lett. 5, 115-130 (2013)

Adjemian, M.K., Lin, C.Y., Williams, J.: Estimating spatial interdependence in automobile type choice with survey data. Transp. Res. Part A Policy Pract. 44(9), 661-675 (2010)

Arentze, T., Timmermans, H.J.: Social networks, social interactions, and activity-travel behavior: a framework for microsimulation. Environ. Plan. B Plan. Des. 35(6), 1012 (2008)

Arentze, T.A., Timmermans, H.J.: A need-based model of multi-day, multi-person activity generation. Transp. Res. Part B Methodol. 43(2), 251-265 (2009)

Axhausen, K.W.: Social networks, mobility biographies, and travel: survey challenges. Environ. Plan. B Plan. Des. 35(6), 981 (2008)

Ben-Akiva, M., Lerman, S.R.: Some estimation results of a simultaneous model of auto ownership and mode choice to work. Transportation 3(4), 357-376 (1974)

Bhat, C.: A new spatial (Social) interaction discrete choice model accommodating for unobserved effects due to endogenous network formation. Transportation (2015). doi:10.1007/s11116-015-9651-9

Bhat, C.R., Koppelman, F.S.: Activity-based modeling of travel demand. In: Hall, R.W. (ed.) Handbook of Transportation Science, pp. 35-61. Kluwer Academic Publishers, Boston (1999)

Bhat, C.R., Pendyala, R.M.: Modeling intra-household interactions and group decision-making. Transportation 32(5), 443-448 (2005)

Bhat, C.R., Sener, I.N.: A copula-based closed-form binary logit choice model for accommodating spatial correlation across observational units. J. Geogr. Syst. 11(3), 243-272 (2009)

Bhat, C.R., Sener, I.N., Eluru, N.: A flexible spatially dependent discrete choice model: Formulation and application to teenagers' weekday recreational activity participation. Transp. Res. Part B Methodol. 44(8-9), 903-921 (2010) 
Bhat, C.R., Sidharthan, R.: A simulation evaluation of the maximum approximate composite marginal likelihood (MACML) estimator for mixed multinomial probit models. Transp. Res. Part B Methodol. 45(7), 940-953 (2011)

Bradley, M., Vovsha, P.: A model for joint choice of daily activity pattern types of household members. Transportation 32(5), 545-571 (2005)

Carrasco, J.A., Cid-Aguayo, B.: Network capital, social networks, and travel: an empirical illustration from concepción, Chile. Environ. Plan. A 44(5), 1066-1084 (2012)

Carrasco, J.A., Farber, S.: Selected papers on the study of the social context of travel behavior. Transp. Res. Part A Policy Pract. 68, 1-2 (2014)

Carrasco, J.A., Miller, E.J.: Exploring the propensity to perform social activities: a social network approach. Transportation 33(5), 463-480 (2006)

Carrasco, J.A., Miller, E.J.: The social dimension in action: a multilevel, personal networks model of social activity frequency between individuals. Transp. Res. Part A Policy Pract. 43(1), 90-104 (2009)

Carrasco, J.A., Hogan, B., Wellman, B., Miller, E.J.: Collecting social network data to study social activitytravel behavior: an egocentric approach. Environ. Plan. B Plan. Des. 35(6), 961 (2008)

Dubernet D., Axhausen, K.W.: Implementing a household joint activity-travel multi-agent simulation tool: first results. Transportation (2015). doi:10.1007/s11116-015-9645-7

Dugundji, E. R, Gulyas, L. Empirical estimation and multi-agent based simulation of a discrete choice model with network interaction effects. In: Proceedings of the 8th International Conference on Computers in Urban Planning and Urban Management, Sendai, Japan (2003a)

Dugundji, E. R., Gulyas, L.: An exploration of the role of global versus local and social versus spatial networks in transportation mode choice behavior in the Netherlands. In: Proceedings of AGENT, Challenges in Social Simulation. University of Chicago, Argonne National Laboratory, Chicago, pp. 437-454 (2003b)

Dugundji, E.R., Gulyás, L.: Sociodynamic discrete choice on networks in space: impacts of agent heterogeneity on emergent outcomes. Environ. Plan. B Plan. Des. 35(6), 1028-1054 (2008)

Dugundji, E.R, Gulyás, L.: Sociodynamic discrete choice applied to intercity travel demand: issues in estimation. In: Proceedings of the Federated Conference on Computer Science and Information Systems (FedCSIS), Wroclaw. Available in IEEE Xplore (2012a)

Dugundji, E.R., Gulyás, L.: Sociodynamic discrete choice on networks in space: role of utility parameters and connectivity in emergent outcomes. Proc. Comput. Sci. 10, 827-832 (2012b)

Dugundji, E.R., Gulyás, L.: Structure and emergence in a nested logit model with social and spatial interactions. Comput. Math. Organ. Theory 19(2), 151-203 (2013)

Dugundji, E.R., Walker, J.L.: Discrete choice with social and spatial network interdependencies: an empirical example using mixed generalized extreme value models with field and panel effects. Transp. Res. Rec. J. Transp. Res. Board 1921, 70-78 (2005)

Dugundji, E.R., Páez, A., Arentze, T.A.: Social networks, choices, mobility, and travel. Environ. Plan. B Plan. Des. 35(6), 956-960 (2008)

Dugundji, E.R., Páez, A., Arentze, T.A., Walker, J.L.: Transportation and social interactions. Transp. Res. Part A Policy Pract 45, 239-247 (2011)

Dugundji, E.R., Scott, D.M., Carrasco, J.A., Páez, A.: Urban mobility and social-spatial contact-introduction. Environ. Plan. A 45, 239-247 (2012)

Fukuda, D., Morichi, S.: Incorporating aggregate behavior in an individual's discrete choice: an application to analyzing illegal bicycle parking behavior. Transp. Res. Part A Policy Pract. 41(4), 313-325 (2007)

Gliebe, J.P., Koppelman, F.S.: A model of joint activity participation between household members. Transportation 29(1), 49-72 (2002)

Gliebe, J.P., Koppelman, F.S.: Modeling household activity-travel interactions as parallel constrained choices. Transportation 32(5), 449-471 (2005)

Goetzke, F.: Network effects in public transit use: evidence from a spatially autoregressive mode choice model for New York. Urban Stud. 45(2), 407-417 (2008)

Goetzke, F., Rave, T.: Automobile access, peer effects and happiness. Transportation (2015). doi:10.1007/ s11116-015-9647-5

Goetzke, F., Andrade, P.: Walkability as a summary measure in a spatially autoregressive mode choice model: an instrumental variable approach. In: Páez, A., Gallo, J.L., Buliung, R.N., Dall'erba, S. (eds.) Progress in Spatial Analysis: Methods and Applications, pp. 217-232. Springer Publishing, New York, (2010)

Goetzke, F., Rave, T.: Bicycle use in Germany: explaining differences between municipalities with social network effects. Urban Stud. 48(2), 427-437 (2011)

Goetzke, F., Weinberger, R.: Separating contextual from endogenous effects in automobile ownership models. Environ. Plan. A 44, 1032-1046 (2012) 
Ho, C., Mulley, C.: Intra-household interactions in transport research: a review. Transport Rev. 35(1), 33-55 (2015)

Joubert, J.W., Meintjes, S.: Computational considerations in building inter-firm networks. Transportation (2015). doi:10.1007/s11116-015-9650-x

Kamargianni, M., Ben-Akiva, M., Polydoropoulo, A.: Incorporating social interaction into hybrid choice models. Transportation 41(6), 1263-1285 (2014)

Kowald, M., Axhausen, K.W.: Focusing on connected personal leisure networks: selected results from a snowball sample. Environ. Plan. A 44(5), 1085 (2012)

Kowald, M., Axhausen, K.W. (eds.): Social Networks and Travel Behaviour. Ashgate Publishing Ltd, Aldershot (2015)

Kowald, M., van den Berg, P., Frei, A., Carrasco, J.A., Arentze, T., Axhausen, K., Mok, D., Timmermans, H., Wellman, B.: Distance patterns of personal networks in four countries: a comparative study. J. Transp. Geogr. 31, 236-248 (2013)

Kroesen, M.: Do partners influence each other's travel patterns? A new approach to study the role of social norms. Transp. Res. Part A Policy Pract. 78, 489-505 (2015)

Kuwano, M., Tsukai, M., Matsubara, T.: Analysis on promoting factors of electric vehicles with social conformity. In: Proceedings of the13th International Conference on Travel Behaviour Research (IATBR), Toronto (2012)

Kuwano, M., Zhang, J., Fujiwara, A.: Dynamic discrete choice model for multiple social interactions. Transp. Res. Rec. J. Transp. Res. Board 2231, 68-75 (2011)

Matous, P., Todo, Y., Pratiwi, A.: The role of motorized transport and mobile phones in the diffusion of agricultural information in Tanggamus Regency, Indonesia. Transportation (2015). doi:10.1007/ s11116-015-9646-6

Okushima, M.: Simulating social influences on sustainable mobility shifts for heterogeneous agents. Transportation (2015). doi:10.1007/s11116-015-9649-3

Páez, A., Scott, D.M.: Social influence on travel behavior: a simulation example of the decision to telecommute. Environ. Plan. A 39(3), 647 (2007)

Páez, A., Scott, D.M., Volz, E.: A discrete-choice approach to modeling social influence on individual decision making. Environ. Plan. B Plan. Des. 35(6), 1055 (2008)

Paleti, R., Bhat, C.R., Pendyala, R.M., Goulias, K.G.: The modeling of household vehicle type choice accommodating spatial dependence effects. In: Proceedings of the 92nd Annual Meeting of the Transportation Research Board, Washington, DC (2013)

Ronald, N., Arentze, T., Timmermans, H.: Modeling social interactions between individuals for joint activity scheduling. Transp. Res. Part B Methodol. 46(2), 276-290 (2012)

Schwanen, T.: Managing uncertain arrival times through sociomaterial associations. Environ. Plan. B Plan. Des. 35(6), 997-1011 (2008)

Scott, D.M., Kanaroglou, P.S.: An activity-episode generation model that captures interactions between household heads: development and empirical analysis. Transp. Res. Part B Methodol. 36(10), 875-896 (2002)

Scott, D.M., Dam, I., Páez, A., Wilton, R.D.: Investigating the effects of social influence on the choice to telework. Environ. Plan. A Policy Pract. 44(5), 1016-1031 (2012)

Scott, D.M., Dugundji, E.R., Páez, A.: The social dimension of activity, travel and location choice behavior. J. Transp. Geogr. 31, 212-215 (2013)

Sener, I.N., Bhat, C.R.: Flexible spatial dependence structures for unordered multinomial choice models: formulation and application to teenagers' activity participation. Transportation 39(3), 657-683 (2012)

Sener, I.N., Eluru, N., Bhat, C.R.: On jointly analyzing the physical activity participation levels of individuals in a family unit using a multivariate copula framework. J. Choice Model. 3(3), 1-38 (2010)

Sharmeen, F., Arentze, T., Timmermans, H.: Predicting the evolution of social networks with life cycle events. Transportation (2015). doi:10.1007/s11116-015-9644-8

Sidharthan, R., Bhat, C.R.: Incorporating spatial dynamics and temporal dependency in land use change models. Geogr. Anal. 44(4), 321-349 (2012)

Sidharthan, R., Bhat, C.R., Pendyala, R.M., Goulias, K.G.: Model for children's school travel mode choice: accounting for effects of spatial and social interaction. Transp. Res. Rec. J. Transp. Res. Board 2213, 78-86 (2011)

Small, K.A., Winston, C.: The demand for transportation: models and applications. In: Gomez-Ibanez, J.A., Tye, W.B., Winston, C. (eds.) Essays in Transportation Economics and Policy: A Handbook in Honor of John R. Meyer. Brookings Institution Press, Washington (1999)

Srinivasan, S., Bhat, C.R.: Modeling household interactions in daily in-home and out-of-home maintenance activity participation. Transportation 32(5), 523-544 (2005) 
Timmermans, H.J., Zhang, J.: Modeling household activity travel behavior: examples of state of the art modeling approaches and research agenda. Transp. Res. Part B Methodol. 43(2), 187-190 (2009)

Train, K.: A structured logit model of auto ownership and mode choice. Rev. Econ. Stud. 47, 357-370 (1980)

Van den Berg, P., Arentze, T., Timmermans, H.: A multilevel analysis of factors influencing local social interaction. Transportation (2015). doi:10.1007/s11116-015-9648-4

Walker, J.L., Ehlers, E., Banerjee, I., Dugundji, E.R.: Correcting for endogeneity in behavioral choice models with social influence variables. Transp. Res. Part A Policy Pract. 45, 362-374 (2011)

Whalen, K.E., Páez, A., Bhat, C.R., Moniruzzaman, M., Paleti, R.: T-communities and sense of community in a university town: evidence from a student sample using a spatial ordered-response model. Urban Stud. 49(6), 1357-1376 (2012)

Frank Goetzke Ph.D., is an Associate Professor in the Urban and Public Affairs Department at the University of Louisville, where he teaches economics and transportation policy. His main research interests include modeling automobile ownership and mode choice decision making, with a focus on social learning and neighborhood spillovers. Prior to earning his Ph.D. in Economics (West Virginia University, 2006), he worked for many years in transportation consulting at Cambridge Systematics.

Regine Gerike Ph.D., is Professor at the Institute for Transport Planning and Road Traffic at the Dresden University of Technology, Germany. Previously she has chaired the Institute for Transport Studies at the University of Natural Resources and Life Sciences (BOKU) in Vienna, Austria. Her research interests include all aspects of transport planning and transport economy, including modelling of travel behaviour, empirical research and holistic approaches to evaluating sustainable mobility.

Antonio Páez Ph.D., is Professor at the School of Geography and Earth Sciences, McMaster University, Canada. He has research interests in the fields of spatial analysis, transportation and land use, and travel behavior. His research has a strong geographical analytical flavor, and has placed a special emphasis on the formal study of the interactions and contextual variations between places and between people. As of 2015, he has authored or co-authored over 90 papers that have been published in journals with international and multidisciplinary audiences. He serves as Editor-in-Chief for the Journal of Geographical Systems since 2008.

Elenna Dugundji Ph.D., is Senior Researcher at CWI, the National Research Institute for Mathematics and Computer Science in the Netherlands. She has over 15 years of experience in transportation demand modelling, discrete choice analysis, land use and infrastructure planning and has provided professional consultancy for strategic regional and corridor development projects. She has also coordinated comprehensive ICT and education innovation projects and has consulted for the World Bank Global Development Learning Network. Her academic research addresses diffusion of information and social influence in dynamic networks, focusing on applications in travel behavior and social media. 